\title{
Trabalhando com o mínimo: a saúde mental infantojuvenil no estado da Paraíba
}

\author{
Working with the minimum: children's mental health \\ in the state of Paraíba
}

Segislane Moésia Pereira da Silva*
Marlene Helena de Oliveira França**

\begin{abstract}
Resumo - Este artigo tem como objetivo trazer algumas reflexões acerca dos impactos do processo de contrarreforma do Estado nas condições objetivas necessárias à efetivação da política de saúde mental infantojuvenil mediante Caps-i do estado da Paraíba. A pesquisa está fundamentada metodologicamente no materialismo históricodialético, de cunho bibliográfico, e utiliza a abordagem qualitativa a partir de uma pesquisa de campo com nove profissionais de três Caps-i em três municípios do estado da Paraíba. São elencadas notas acerca do financiamento da política de saúde mental, da estrutura física e da composição das equipes multiprofissionais desses centros. Os resultados comprovam um desmonte por meio do subfinanciamento, da precarização presente nas condições materiais dos centros e da ausência de formação das equipes multiprofissionais, que estão cada vez mais reduzidas, em face de uma elevada demanda.

Palavras-chave: contrarreforma; desmonte social; saúde mental infantojuvenil; Caps-i.
\end{abstract}

\begin{abstract}
This article aims to reflect on the impacts of the State Counter-Reformation process on the objective conditions necessary for the implementation of children's mental health policy through Caps-i in the state of Paraíba. The research is methodologically based on historical dialectical materialism, of bibliographic nature, and uses a qualitative approach from field research that encompassed nine professionals from three Caps-i in three municipalities in the state of Paraíba. Notes are made about funding for the mental health policy, the physical structures, and the composition of the multidisciplinary teams of these centers. Results prove an intentional
\end{abstract}

\footnotetext{
* Assistente Social, graduada pela Universidade Federal de Campina Grande (UFCG). Mestra em Direitos Humanos, Cidadania e Políticas Públicas pela Universidade Federal da Paraíba (PPGDH-UFPB). Residente no Programa de Pósgraduação em Residência Multiprofissional em Saúde Mental, do Núcleo de Estudos em Saúde Coletiva da Universidade Federal da Paraíba (RESMEN/NESC/UFPB). Especialista em Formação em Educação pela Universidade Paulista. E-mail: segislane@outlook.com. ORCID: https://orcid.org/0000-0003-4906-1480.

${ }^{* *}$ Doutora em Sociologia pela UFPB. Possui graduação em Direito (2017) e em Serviço Social (2000) pela Universidade Federal da Paraíba. Mestrado em Serviço Social pela Universidade Federal da Paraíba (2003). Atualmente é Professora Adjunto III da Universidade Federal da Paraíba, lotada no Departamento de Habilitações Pedagógicas-CE. E-mail: marlenecel@hotmail.com. ORCID: https://orcid.org/0000-0003-1844-3451.
} 
dismantling through underfunding, precariousness in material conditions of the centers, and the lack of training for multidisciplinary teams, which are increasingly reduced while demand rises.

Keywords: counter-reformation; dismantling; children's mental health; Caps-i.

\section{Introdução}

A política nacional de saúde mental vive tempos desafiadores e, parafraseando Amarante (2019), as ameaças não se encontram apenas perante a reforma psiquiátrica, mas atingem também os avanços conquistados no campo da atenção psicossocial e no SUS. O desmonte dessa política vem tomando crescentes proporções nos últimos anos diante do processo de contrarreforma do Estado brasileiro, somando-se ao avanço do neodesenvolvimentismo, do neoconservadorismo e da retomada do poder pela extrema direita desde o golpe político instaurado no Brasil em 2016.

Em 2021 houve a comemoração de mais de 20 anos da promulgação da Lei $n^{\circ} 10.216$, de 2001, que estabeleceu um novo modelo de atenção à saúde mental no país - o modelo psicossocial -, visando à garantia da proteção integral às pessoas com transtornos mentais. Essa lei é transpassada pelo ataque contrarreformista, responsável pelo desmonte cotidiano dessa política pública. Tem-se como uma das principais medidas adotadas, e que referenda esse ataque, a implementação da Emenda Constitucional no 95, de 2016, que congelou os investimentos em saúde e, consequentemente, afetou o financiamento da política de saúde mental e dos Caps.

Com isso, surgem algumas inquietações: os Caps, enquanto dispositivo fundamental de serviço substitutivo do modelo manicomial e que compreende um novo paradigma da reforma psiquiátrica, têm vivenciado que tipos de impactos? Quais as atuais condições objetivas com relação ao financiamento, à garantia de estrutura e à composição das equipes desses centros? Trata-se de questionamentos pertinentes, visto que os estudos voltados para a problemática das condições objetivas para a saúde mental ainda são bastante escassos (TRAPÉ; CAMPOS, 2016).

É a partir dessa perspectiva que este estudo, fruto de uma pesquisa de dissertação de mestrado em Direitos Humanos, Cidadania e Políticas Públicas da Universidade Federal da Paraíba (PPGDH-UFPB), teve como principal objetivo levantar apontamentos acerca das condições objetivas de implementação da política de saúde mental infantojuvenil nos Caps-i.

Para a realização deste estudo, foi utilizado o método materialista histórico-dialético, com finalidade de compreender a problemática em sua totalidade diante dos determinantes políticos e sociais que abarcam a temática. Com respaldo na pesquisa de natureza qualitativa, realizou-se um estudo de campo após aprovação pelo Comitê de Ética em Pesquisa do 


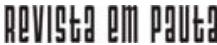

\} TRABALHANDO COM O MÍNIMO - SILVA, S. M. P.; FRANÇA, M. H. O. \}

DOI: $10.12957 /$ REP.2022.63445

Centro de Ciências da Saúde da Universidade Federal da Paraíba (CEP/ CCS), sob Caae ${ }^{\circ}$ 31660920.2.0000.518-, com nove profissionais de saúde mental atuantes em três Caps-i do Estado da Paraíba, selecionados por mesorregião (Sertão, Agreste e Região da Mata). O material empírico foi produzido com base nos questionários e nas entrevistas semiestruturadas conduzidas no período entre os meses de agosto e outubro de 2020, seguido da análise de conteúdo proposta por Bardin (2011).

Este artigo inicia-se com uma breve análise acerca da saúde mental e da contrarreforma do Estado brasileiro. Em seguida, será evidenciada a importância das condições objetivas da política de saúde mental para a garantia da efetivação das ações e serviços de saúde mental, bem como a análise sobre questões referentes aos recursos de financiamento público, à oferta de equipamentos estruturais, físicos e humanos, e à forma de organização das equipes multiprofissionais nos Caps, findando-se com as considerações finais.

\section{Saúde mental na contrarreforma do Estado brasileiro}

Nos estudos de saúde mental aprende-se que, por volta da década de 1970, como resultado da crise na Divisão Nacional de Saúde Mental (Dinsan) - decorrente das péssimas condições que os hospitais psiquiátricos ofereciam -, nascia o Movimento dos Trabalhadores em Saúde Mental (MTSM), o qual Amarante e Nunes (2018) consideram o primeiro sujeito coletivo com vistas à reformulação do modelo psiquiátrico. Para Amarante e Nunes (2018, p. 2068),

é neste cenário de redemocratização e luta contra a ditadura, relacionando a luta específica de direitos humanos para as vítimas da violência psiquiátrica com a violência do estado autocrático, que se constituiu o ator social mais importante no processo de Reforma Psiquiátrica (RP).

Ou seja, esse processo é reflexo da luta histórica de profissionais, usuários e familiares, assim como da sociedade, perante as condições desumanas e degradantes do modelo manicomial e biomédico do trato com a saúde mental ao longo da história das instituições psiquiátricas no Brasil. Esse movimento teve inspiração nos ideais de Franco Basaglia, que reivindicava mudanças no modelo hospitalar, propondo o fim das internações, da desumanização vivida nesses locais, entre outros ao redor do mundo.

Quanto ao cuidado com a saúde mental na infância e adolescência brasileiras, no livro Holocausto brasileiro, a autora Daniela Arbex (2013) apresenta inúmeros casos de crianças e adolescentes enviados ao Hospital Colônia de Barbacena, que ficou conhecido nacionalmente como exemplo de instituição violadora de direitos humanos, onde a morte social operava 


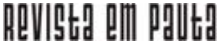

\} TRABALHANDO COM O MÍNIMO - SILVA, S. M. P.; FRANÇA, M. H. O. \}

DOI: $10.12957 /$ REP.2022.63445

constantemente. Os pequenos, com qualquer tipo de doença mental ou física, e até muitas vezes sem nenhum diagnóstico de problemas mentais, apenas rejeitados pelas famílias e sociedade, morriam de frio, desnutrição, infecções, verminoses (ARBEX, 2013).

A falta de uma política de saúde mental para crianças e adolescentes levou a uma desconsideração dessas pessoas como sujeitos de direitos durante muito tempo. Como cita Amarante (2019), somente com as reformas sanitária e psiquiátrica, com a Constituição Federal brasileira de 1988, com a Lei no 10.216 de 2001, atreladas ao Estatuto da Criança e do Adolescente (ECA), é que tivemos algumas transformações iniciadas, contudo, ainda de forma bastante vagarosa em comparação com os adultos.

A partir de então, especificamente no campo da saúde mental infantojuvenil, tivemos a forte conquista dos Centro de Atenção Psicossocial Infantojuvenis (Caps-i), que vieram a ser estabelecidos por meio da Portaria no 336, de 2002 (BRASIL, 2002). Nesses rumos, as crianças e os adolescentes, hoje, estão assegurados constitucionalmente por uma rede de proteção integral, em especial, uma atenção em saúde que leva em consideração os determinantes e condicionantes do processo saúde-doença a partir do conceito ampliado de saúde, ultrapassando a mera ausência de doenças e tendo em vista os aspectos mentais e sociais, como preconiza a Constituição Federal de 1988.

No Brasil, entretanto, na década de 1990, é gestado um projeto burguês visando ao processo de ajuste do Estado, que Behring (2008) denomina de "contrarreforma", em resposta à crise estrutural do capital. As medidas neoliberais de contenção dessa crise configuram-se totalmente regressivas em relação aos direitos sociais, inclusive na saúde. Além disso, esse processo perpassa os mais de 30 anos de implantação do SUS e possui algumas particularidades, a depender de cada governo que gesta essa política pública.

De forma sucinta, o neoliberalismo incorporado no Brasil a partir do governo de Collor de Mello veio ganhar forças no governo Fernando Henrique Cardoso (FHC), quando-assistimos ao início de ataques às políticas públicas de saúde e saúde mental de forma mais evidente e predominante, sobretudo a partir do Plano Diretor da Reforma do Estado (PDRE) ${ }^{1}$, das privatizações e da abertura à terceirização na saúde. Em seguida, o chamado sonho pela transformação social, que muitos depositaram no governo de Luiz Inácio Lula da Silva (Lula), não foi realizado em sua plenitude. Contudo consideramos que, independentemente do governo, essa transformação seria utópica, pois a hegemonia capitalista impera nas correlações de forças existentes. Por outro lado, é inegável que foi durante o governo Lula que houve um divisor de águas no campo das políticas públicas e sociais, como

1 O Plano Diretor da Reforma do Estado foi aprovado depois de uma ampla discussão pela Câmara da Reforma do Estado, em sua reunião de 21 de setembro de 1995, e visou a uma forte reforma na administração pública brasileira. 
na saúde, por meio da aprovação e da implantação de novos programas sociais.

No governo Dilma Rousseff, a primeira mulher eleita para a presidência da República, também do Partido dos Trabalhadores (PT), deu-se continuidade a uma agenda propositiva na saúde. Porém, o poderio burguês pela economia neoliberal, atrelado ao patriarcalismo no Brasil, foi suficiente para efetivar um golpe de Estado - parlamentar, jurídico, midiático e, sobretudo, misógino -, comprovando o quanto o país é submisso às forças econômicas e políticas capitalistas, que retiraram Dilma Rousseff do cargo presidencial em 2016.

Após o golpe, tivemos o retorno de setores neoconservadores e reacionários ao poder no país com a chegada do governo de Michel Temer. Retomou-se o processo de contrarreforma do Estado, de forma ainda mais avassaladora que no governo de FHC, o que atingiu de maneira direta a política de saúde. Além disso, o avanço do neoconservadorismo abriu brechas para o neofascismo e para as tentativas cada vez mais frequentes de desmonte da política de saúde e saúde mental evidentes no atual governo de Jair Messias Bolsonaro, eleito em 2018, que coloca a política de saúde mental e os ideais da reforma psiquiátrica brasileira "à beira do abismo e ao encontro do absurdo", conforme ressaltam Correia, Martins e Requião (2019, p. 2).

Nessa lógica avaliamos o processo de garantia e efetivação dos direitos humanos e de saúde mental de crianças e adolescentes, especialmente por meio do funcionamento dos Caps-i, que vivenciam uma precarização perante os ataques e desmontes sociais. Diante disso, indagamos: quais as condições objetivas para a garantia da saúde mental para esses sujeitos e como todo esse processo afeta a atenção à saúde mental infantojuvenil?

\section{A garantia da atenção à saúde mental infantojuvenil nos Caps-i}

Marx (1988, p. 47) assinala que "o modo de produção da vida material condiciona o processo de vida social, política e intelectual. Não é a consciência dos homens que determina o seu ser; ao contrário, é o seu ser social que determina sua consciência". Nessa perspectiva consideramos que os meios materiais condicionam a existência humana e que o modo de produção historicamente determina a interação entre o homem, a natureza e os outros seres, assegurando a manutenção da existência social.

As condições objetivas nessa ótica são aquelas relativas à produção material da sociedade postas na realidade material. De acordo com Guerra (2002), a propriedade dos meios de produção, a divisão social e sexual do trabalho, a conjuntura, os espaços sócio-ocupacionais, os objetos e os campos de intervenção e as relações e condições materiais de trabalho são 


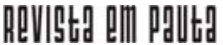

\} TRABALHANDO COM O MÍNIMO - SILVA, S. M. P.; FRANÇA, M. H. O.

DOI: $10.12957 /$ REP.2022.63445

condições objetivas fundamentais para a garantia da efetivação de direitos, uma vez que é por meio delas que se dá a implementação e a oferta das ações e serviços mediante as políticas públicas.

É sabido, contudo, que o sistema capitalista produz e reproduz desigualdades, especialmente em sua forma contemporânea, por meio do neoliberalismo, que visa incessantemente ao ataque aos direitos conquistados historicamente, especialmente no campo da proteção social da saúde. A garantia do direito à saúde mental no Brasil é explicitada a partir de um arcabouço normativo e intelectual que vem sendo formulado e gestado desde a década de 1990; portanto, são inegáveis as inúmeras mudanças e avanços na oferta das ações e serviços de saúde e saúde mental que têm o Estado como o principal responsável.

Os princípios e diretrizes que estabelecem as formas de organização, distribuição e oferta da política de saúde mental brasileira, todavia, não são suficientes para a garantia da sua plena efetivação. Isso porque sofrem constantes percalços devido às condições objetivas de implementação da política, sobretudo em razão das dificuldades concretas de recursos, de cortes no financiamento público e para a própria estrutura física dos Caps-i, que visam a assegurar a qualidade da oferta das ações e dos serviços diante da crescente demanda pela saúde mental nas relações sociais capitalistas, patriarcais e racistas que vivemos.

\section{Financiamento e recursos: "trabalhando com o mínimo do mínimo $^{\prime \prime 2}$}

A Portaria no 3.089, de dezembro de 2011, dispõe acerca do financiamento para manutenção mensal, de acordo com cada modalidade dos Caps, para custeio das ações e dos serviços ofertados. De acordo com a portaria, o valor fixo atual destinado ao custeio das ações de atenção psicossocial dos Caps-i é de R\$32.130,00 mensais. É relevante sinalizar que, desde o ano de 2006, como afirma Delgado (2010), houve uma inversão dos gastos do Ministério da Saúde com a saúde mental, cujo maior montante passou de hospitalar para extra-hospitalar, em razão da queda do número de internações psiquiátricas causada pela redução dos leitos hospitalares e pelo avanço dos serviços extra-hospitalares, como no caso dos Caps.

De acordo com o documento Saúde mental em dados 12 (BRASIL, 2015), a Portaria $n^{\circ} 3.089 / 2011$ possibilitou um importante salto no que tange ao financiamento dos Caps. Ainda se pôde constatar o enorme avanço nos investimentos dos Caps como nova forma de atenção à saúde mental,

2Salientamos que a frase "trabalhando com o mínimo do mínimo" utilizada no tópico faz referência a um trecho da fala de um dos participantes de nossa pesquisa durante as entrevistas. 


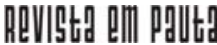

\} TRABALHANDO COM O MÍNIMO - SILVA, S. M. P.; FRANÇA, M. H. O. \}

DOI: $10.12957 /$ REP.2022.63445

especialmente após a Portaria no 3.089/2011 entrar em vigor. Entretanto o financiamento e os recursos alocados para os Caps-i no estado da Paraíba se demonstram ínfimos, como confirmado na fala do gestor de um Caps-i do Sertão do estado, que, ao ser indagado, demonstrou uma evidente insatisfação com o valor hoje destinado:

Considerando a importância, a essencialidade do serviço, a demanda crescente de usuários, acredito que os valores devem ser maiores! Atualmente a demanda de sofrimentos psíquicos vem aumentando cada vez mais [...] é necessária a aquisição de equipamentos, materiais e insumos mensais para o funcionamento das oficinas terapêuticas e de todos os serviços. (Coordenador A).

Note-se que o gestor relata a relevância de maiores investimentos no Caps-i, especialmente pelo fato de haver um aumento da demanda pelos serviços, o que consequentemente resulta na necessidade de uma expansão da equipe, dos materiais, dos equipamentos e dos insumos.

Delgado (2010) alerta sobre a problemática do financiamento da saúde mental, o qual, mesmo tendo evoluído nas últimas décadas, ainda é bastante irrisório. O sistema público brasileiro de saúde investe apenas cerca de $2,7 \%$ do seu orçamento em saúde mental; o indicado é de que fosse aproximadamente $4 \%$, o que se justifica pelo fato de a demanda pela saúde mental atingir pelo menos $25 \%$ da população em geral em algum momento da vida e $12 \%$ ao longo de um ano (DELGADO, 2010). Além disso, consoante um dos profissionais:

Tive experiência internacional, então, em comparado com outros países, nunca tivemos recursos vastos para a saúde. Nunca tivemos um olhar que deveríamos ter tido para o direito à saúde. Obviamente o que temos hoje com o SUS nem se compara a antes do SUS, mas o que percebemos é um desmonte do que foi conquistado até então, um desmonte do SUS que afeta diretamente a saúde mental né?! (Profissional B).

Fica então evidenciado que, com o resultado do baixo financiamento dos Caps-i, há uma escassez de recursos para as condições objetivas de efetivação da política de saúde mental para as crianças e adolescentes dessas unidades. Como afirma o Profissional D de um Caps-i: "Uma das maiores dificuldades é a falta de recursos, com relação ao incentivo a coisas que realmente precisamos, como brinquedos, jogos, o local lúdico adequado". O profissional ressalta que os materiais que o Caps-i possui se encontram sucateados: "muitas crianças estão cansadas de ver o mesmo jogo, aí nos perguntam 'ô tia, não tem outro jogo não?'”. Todavia, como forma de superação dessa dificuldade, profissionais relataram que muitas vezes utilizam recursos próprios para adquirirem materiais novos que assegurem a atuação profissional. 
Eu acho que a gente vai tentando superar, enfim, enfrentar diariamente os desafios. Existem restrições, sabe? Em relação a recurso, materiais [...] nós, colegas, vamos nos ajudando. Se tá faltando num serviço e no local que fornece ainda não tá disponível, então ainda quem tem vai suprindo as necessidades. A gente vai se adaptando. A gente vai aprendendo muito a se adaptar às coisas. A gente colabora, faz um 'junte' e compra, é nesse sentido! (Profissional C).

As narrativas de profissionais que declararam que pagam do próprio salário a compra de materiais básicos revelam a precarização do trabalho, a falta de investimentos públicos e, ao mesmo tempo, o compromisso dos(as) profissionais, de forma individual e coletiva. Isso está evidenciado no fato de recorrerem à chamada "vaquinha" para assegurar condições mínimas para o trabalho. Em um dos depoimentos, o entrevistado afirmou estar cansado de trabalhar "com o mínimo do mínimo", ou ainda com a reutilização de brinquedos.

Já cheguei a comprar com recurso próprio! Comprei já caixa de lápis. Agora mesmo no Setembro Amarelo tivemos que comprar os materiais para as lembrancinhas e ornamentação, foi tudo do nosso bolso, não veio recurso! Disseram que iam solicitar esse recurso, mas até agora nada. (Profissional B).

Percebe-se que, imersos no cotidiano profissional e submetidos a uma lógica de trabalho algumas vezes insuficiente, os profissionais lançam mão de recursos próprios, mesmo diante de baixos salários, e revelam, portanto, uma porosidade na fronteira entre envolvimento profissional e envolvimento humano.

No estudo realizado, destaca-se como um dos principais instrumentos neoliberais de ataque e desmonte da saúde no país - a Emenda Constitucional no 95 (EC-95), aprovada em 2016 no governo Temer aumenta as incertezas quanto ao financiamento da política de saúde pública brasileira. O cálculo dos impactos dessa medida já foi apresentado por vários teóricos, além de ser destacada a preocupação com a continuidade de um sistema público diante das ofensivas em defesa da privatização do SUS, pregada pelos governos hegemônicos atuais. Afinal, o que será do SUS? Nessa perspectiva, busca-se analisar o nível de conhecimento e perspectivas dos profissionais acerca da EC no 95/2016.

Em unanimidade, os sujeitos da pesquisa conduzida relataram conhecer a Emenda Constitucional $n^{\circ}$ 95, no entanto, a maioria afirmou que possui uma compreensão mínima, com informações obtidas apenas pela mídia, em noticiários ou discussões informais do cotidiano. "Eu sei resumidamente que aconteceu o congelamento, mas eu não cheguei a ler a emenda. A gente que trabalha fica trocando essas angústias em relação a isso, mas apenas nos corredores" (Profissional C). 


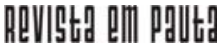

\} TRABALHANDO COM O MÍNIMO - SILVA, S. M. P.; FRANÇA, M. H. O. \}

DOI: $10.12957 /$ REP.2022.63445

Mesmo sem demonstrar um conhecimento aprofundado acerca da referida medida, identificamos uma certa aflição que a EC no 95/2016 causa nos profissionais, pois há o consenso de que o SUS, para a sua consolidação, necessita de financiamento e não de corte de investimentos, conforme o relato de indignação de um profissional sobre a referida emenda:

Eu estaria mentindo se dissesse que estou totalmente acompanhando. Por dentro eu não estou! Agora, o conhecimento? Tenho! Se você congela a educação e a saúde, o que que você quer? Você quer acabar com o SUS! Né não?! (Profissional D).

Outro profissional entrevistado desabafou suas angústias acerca do medo de um possível retrocesso ao modelo manicomial de atenção à saúde mental:

Se você não dá recurso suficiente pra que um trabalho que vinha sendo desenvolvido não venha a dar continuidade, há retrocessos. Tudo que for para retirar da saúde, seja primário, secundário, terciário... Porque os hospitais precisam, os ambulatórios precisam e os Caps também precisam, como é o caso do Caps-i, então há retrocesso! Só penso na capacidade de mudar o sistema, voltar os hospitais psiquiátricos, porque se acontecer vai ser um retrocesso grande, enorme! E isso nos aflige! (Profissional D).

Nota-se, portanto, que as decisões políticas que vêm sendo tomadas pelo Estado brasileiro em relação à saúde mental, a exemplo das mudanças na política nacional de saúde mental e a edição da própria EC no 95/ 2016, não são discutidas pelos profissionais no espaço de trabalho como assuntos de reunião. A coordenação de um dos Caps-i alega que "as questões de financiamento são raramente discutidas a nível de gestão (diretores, coordenadores, gerentes e secretários de saúde). Nas conferências municipais de saúde e conferências nacionais de saúde mental que sempre é discutido um eixo sobre financiamento" (Coordenador A).

É possível perceber que esse debate não ocorre nos Caps, a exemplo de os Caps-i, trabalhadores, coordenadores ou mesmo secretários de saúde refletirem e discutirem somente nas conferências. Azevedo (2010) enfatiza que essas discussões, além de serem fundamentais, precisam produzir progressos, pois a problemática do financiamento ainda representa um entrave na consolidação do SUS e da reforma psiquiátrica no que tange à sua regulamentação e efetivação.

\section{Estrutura e característica física dos Caps-i: a fragilização dos serviços}

Além do financiamento, outro grave problema que prejudica a efetivação da promoção da saúde mental para crianças e adolescentes nos 


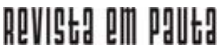

\} TRABALHANDO COM O MÍNIMO - SILVA, S. M. P.; FRANÇA, M. H. O. \}

DOI: $10.12957 /$ REP.2022.63445

Caps-i diz respeito à estrutura desses centros. Em suas diferentes modalidades, os Caps-i são pontos estratégicos da Raps e operam em territórios compreendidos não apenas como espaços geográficos, mas territórios de pessoas, de instituições, dos diversos cenários nos quais se desenvolve a vida dos usuários e dos seus familiares, e constituem-se como um lugar na comunidade (BRASIL, 2004).

Sendo assim, é comum os Caps ocuparem o espaço de promotor da vida e do cuidado, e possuírem a missão de garantir o exercício da cidadania e da inclusão social de usuários e familiares. Dessa forma, o Caps-i, em especial, passaram a ser então o novo lugar social para as crianças e adolescentes com experiência decorrente de transtornos mentais, incluindo aqueles por dependência de álcool e outras drogas.

Os Caps-i devem ser implantados em municípios acima de 70 mil habitantes, e o estado da Paraíba possui até o momento um total de apenas 12 unidades de Caps-i. De acordo com o Manual de estrutura física dos Caps (BRASIL, 2013), esses espaços destinados ao cuidado e apoio desses sujeitos são também projetos de vida e de exercício de direitos, e, nessa perspectiva, os "espaços Caps" devem ser projetados considerando algumas características e particularidades.

A primeira afirmação referente à construção dos Caps é de que são serviços de portas abertas, em seu sentido mais literal e simbólico, rompendo totalmente com o modelo asilar e privatista de liberdade antes aplicado. Além disso, devem ser desenvolvidos e disponibilizados acoIhimento, apoio, cuidado e suporte aos usuários e familiares. Também devem ser um serviço substitutivo, territorial, aberto e comunitário. Acerca dos ambientes que os Caps precisam possuir, é fundamental que o espaço físico tenha recepção, salas de atendimento individualizado, salas de atividades coletivas, espaços de convivência, banheiros, sala de aplicação de medicamentos e posto de enfermagem, quarto coletivo, sala administrativa, sala para arquivo e almoxarifado, refeitório e copa, banheiro, depósito de material de limpeza, rouparia, abrigo de recipientes de resíduos (lixo) e área com espaço para embarque e desembarque de ambulância, bem como área externa de convivência ${ }^{3}$ (BRASIL, 2013).

No momento da pesquisa, observou-se que o Caps-i localizado no Sertão do estado se encontra em uma situação de total precariedade quanto à sua estrutura. No momento do estudo, o Caps-i não possuía sequer estrutura própria e se encontrava em funcionamento em uma sede do Centro de Referência em Saúde do Trabalhador (Cerest) ${ }^{4}$. Tais unidades - Cerest não são destinadas a dar suporte e atendimento a crianças e adolescentes,

\footnotetext{
${ }^{3}$ Para aprofundamentos acerca das características da estrutura física dos Caps, sugerimos ver na íntegra: BRASIL. Ministério da Saúde. Manual de estrutura física dos Caps. 2013. Disponível em: http://189.28.128.100/dab/docs/sistemas/ sismob/manual_ambientes_caps_ua.pdf. Acesso em: 9 dez. 2020.

${ }^{4}$ Os Centros de Referência em Saúde do Trabalhador (Cerest) são unidades que buscam promover ações para melhorar as condições de trabalho e a qualidade de vida do trabalhador por meio de serviços de prevenção e vigilância.
} 


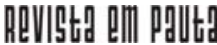

\} TRABALHANDO COM O MÍNIMO - SILVA, S. M. P.; FRANÇA, M. H. O. \}

DOI: $10.12957 /$ REP.2022.63445

mas a trabalhadores urbanos e rurais. Nas palavras de um dos profissionais atuantes na instituição:

Atualmente acho que é o pior estágio que eu peguei o Caps-i, porque a gente nem uma sede própria temos. Até temos, mas não estamos na sede desde o início do ano. Aí colocaram a gente pra atuar no Cerest com uma sala emprestada, né? Atualmente estamos atuando meio que como ambulatorial nesse centro. (Profissional A).

O relato do profissional demonstra a insegurança e a preocupação em não ter disponível uma unidade específica para a atuação. Trata-se de um problema antigo, pois, em um estudo realizado entre 2015 e 2018 por Medeiros e Tomé (2018), no mesmo Caps-i do Sertão do estado, as autoras afirmaram que a instituição funcionava até 2018 em uma casa alugada, com salas de atendimento, brinquedoteca, área de uso comum, cozinha, banheiros, refeitório, piscina. Todavia, a justificativa de uma reforma no ambiente fez com que o serviço fosse direcionado ao Cerest desde o início de 2018 até o mês de realização da presente pesquisa, ou seja, quase um ano após, o mesmo Caps-i ainda não contava com estrutura própria.

Medeiros e Tomé (2018) acrescentam que já havia problemas relacionados ao processo de gestão, ao número crescente de demanda, à precarização das condições de trabalho, às condições de vínculo empregatício e à deficitária estrutura física do centro. A escassez de uma estrutura física adequada para o funcionamento dos serviços constitui uma problemática, sem falar que o Caps-i do Sertão, assim como os demais, atende inúmeras outras cidades circunvizinhas, pois nem todos os municípios possuem unidade de Caps-i.

O Caps-i, foco da presente investigação, atende em média 24 cidades circunvizinhas, o que sobrecarrega o centro. Ao ser questionado sobre os desafios para atuar no Caps-i, o profissional destacou:

O primeiro grande desafio é não termos uma estrutura própria, uma estrutura própria física, uma base, o que prejudica totalmente o desempenho das ações, né? Ações sociais, coletivas, com a família, que deveriam ser a proposta do Caps infantil, não são viáveis. E isso não se justifica pela pandemia, se justifica desde antes [...] eu diria as condições estruturais, as condições climáticas, as condições salariais extremamente difíceis, a negação de direitos fundamentais, nessa pandemia muitos profissionais trabalhando sem salubridade. (Profissional B).

A sólida percepção que se extrai com a fala desse profissional é a de que o atual local onde está situado o Caps-i desponta um enorme desafio para a atuação profissional e tem prejudicado as ações com as crianças, adolescentes e familiares. Essa escassez de local próprio torna a proposta original do Caps-i inviável. Ademais, é importante destacar que, no Sertão 


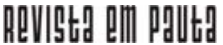

\} TRABALHANDO COM O MÍNIMO - SILVA, S. M. P.; FRANÇA, M. H. O.

DOI: $10.12957 /$ REP.2022.63445

paraibano, o clima predominante é o semiárido, caracterizado como quente, e exige uma atenção ainda maior diante das condições climáticas dessas instituições. A falta de ares-condicionados ou de melhores condições climáticas do ambiente local prejudicam a própria atuação profissional, segundo o depoimento de um dos entrevistados. Ao ser indagado sobre se o Caps-i do Sertão oferece as condições necessárias para o exercício do trabalho especializado, outro profissional expressou em tom de desabafo:

De jeito nenhum! Pra o objetivo do Caps infantil a gente não tem o espaço, sabe? Eu tenho uma sala que dá para fazer o que me cabe hoje, porque estamos atendendo tipo ambulatório. A gente faz aquele acolhimento inicial do paciente, faz consulta e tal, mas para o objetivo mesmo do Caps, de atividades, de recreação, a gente não se encontra de jeito nenhum. (Profissional A).

Para haver uma estrutura própria e adequada do Caps para os usuários - pois muitos podem necessitar de acompanhamento contínuo com atendimentos semanais e exigir a presença dos familiares -, assim como para os próprios profissionais, é de suma relevância que haja a organização do espaço físico para a oferta dos serviços, com maior qualidade.

A Paraíba é considerada referência na saúde mental e isso se deve em grande parte ao município de Campina Grande (BRASIL, 2015), inclusive essa é a única cidade do estado que possui dois Caps-i. Entretanto, assim como os demais centros, o Caps-i localizado no Agreste paraibano atende não somente à demanda do município, mas à de várias outras cidades circunvizinhas, chegando a acompanhar uma média de 400 usuários, de acordo com a coordenação do Caps-i, o que sobrecarrega o centro. Quanto ao Caps-i localizado na Região da Mata do estado paraibano, os profissionais participantes deste estudo, que atuam na unidade, avaliaram-no como detentor de uma boa estrutura física.

\section{Caracterização das equipes multiprofissionais: expansão ou redução?}

As complexidades das transformações sociais e das demandas em saúde vêm exigindo profundas mudanças nas formas tradicionais de abordagem, e a interdisciplinaridade e transdisciplinaridade vêm sendo apontadas como saídas para essas questões. A ideia de SUS que possuímos, a partir de um conceito ampliado de saúde baseado no princípio da universalidade e integralidade, tem em vista estratégias que visam justamente ao enfrentamento dessa complexidade inerente à saúde.

Para isso, é apontada a importância da articulação dos saberes profissionais a fim de se atingir a integralidade do sujeito de acordo com suas necessidades e para superar um modelo centrado no saber biomédico, 


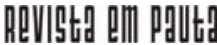

\} TRABALHANDO COM O MÍNIMO - SILVA, S. M. P.; FRANÇA, M. H. O. \}

DOI: $10.12957 /$ REP.2022.63445

conforme preconiza a reforma psiquiátrica. De acordo com o Manual de estrutura física dos Caps, a equipe mínima para atuação nos Caps-i é de: um médico psiquiatra, neurologista ou pediatra com formação em saúde mental; um enfermeiro; quatro profissionais de nível superior, dentre psicólogos, assistentes sociais, terapeutas ocupacionais, pedagogos, educadores físicos ou outros profissionais necessários ao projeto terapêutico; e cinco profissionais de nível médio, dentre técnicos e/ou auxiliares de enfermagem, técnicos administrativos, técnicos educacionais e artesãos (BRASIL, 2013).

A partir da pesquisa realizada, todavia, percebeu-se que, embora haja a determinação de uma equipe mínima, diante da demanda elevada, a quantidade de profissionais se torna insuficiente para atender com eficiência a todos os usuários dos Caps-i. Durante o estudo, as equipes multiprofissionais dos Caps-i que compunham o universo da pesquisa estavam assim caracterizadas: Caps-i do Sertão com 11 profissionais; Caps-i do Agreste com 18 profissionais e Caps-i da Região da Mata com 14 profissionais. As equipes eram constituídas de assistentes sociais, psicólogos, enfermeiros, psiquiatras e outros trabalhadores de nível médio e técnico. Assim, avalia-se que, nesses Caps-i, há a necessidade de fonoaudiólogos e também de uma menor rotatividade de profissionais nas equipes, uma vez que a maioria possui apenas relações contratuais temporárias.

A elevada demanda é outro desafio, na medida em que sobrecarrega as equipes e dificulta a garantia da integralidade da atenção à saúde mental dessas crianças e adolescentes, conforme o depoimento de um dos entrevistados do Caps-i no Sertão paraibano, ao expressar que "a demanda é enorme, inesgotável! Todos os dias temos pacientes novos. Eu atendo em média 8 a 10 pacientes por período no dia" (Profissional B). É perceptível na fala desse profissional que há a preocupação, o sentimento de indignação perante a enorme demanda que é encaminhada para o seu setor, além de enfatizar que o seu conselho de classe profissional esclarece que o atendimento máximo a ser realizado deve ser de oito usuários diários. Isso comprova a necessidade não só desse Caps-i no Sertão quanto da melhoria ou adoção de estrutura física própria, mas também da ampliação da equipe multiprofissional para atender de forma efetiva à demanda.

A equipe vem reduzindo bastante, tanto que a gente só tem hoje uma psicóloga e duas enfermeiras, e isso porque são efetivas. Não tem monitores, não tem educadores físicos, não tem outros profissionais necessários para o cuidado com as crianças. Não tem material, não tem sede. Então acho que a situação vem se precarizando bastante. Tô começando a ver agora as necessidades. (Profissional A).

O profissional ressalta que, além de a equipe ser reduzida, também há a falta de monitores, educadores físicos e outros profissionais necessários para atender às demandas. A demanda excessiva e a escassez de um número 


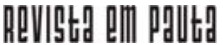

\} TRABALHANDO COM O MÍNIMO - SILVA, S. M. P.; FRANÇA, M. H. O. \}

DOI: $10.12957 /$ REP.2022.63445

maior de profissionais na equipe não se restringem apenas ao município no Sertão do estado. No Caps-i do Agreste, houve o seguinte relato:

[...] a demanda é muito grande, principalmente de adolescentes, e muitas vezes eles precisam do atendimento individualizado, né? Há necessidade de profissionais na área de psicólogos para atendê-los. Então nós temos um número muito reduzido de psicólogos para atender essa clientela. A grande maioria dos adolescentes que nós recebemos muitas vezes são adolescentes que vêm encaminhados do hospital porque algum momento tentou suicídio num momento de angústia. Estão com depressão [...] tem vários fatores que interferem no bom trabalho e no serviço, né? Principalmente quando você sabe que usuário precisa, mas não tem um profissional ali que tenha disponibilidade para atender, então isso pra a gente é muito complicado, né?! (Profissional D).

A partir da fala do profissional, podemos identificar que a demanda sobrecarrega a equipe multiprofissional e reafirma a necessidade de contratação de mais profissionais e de outras especialidades. Delgado (2010) salienta que, mesmo que os investimentos em saúde mental tenham dobrado com a reforma psiquiátrica, ainda não são o suficiente, sobretudo diante dos cortes recorrentes no atual governo. Assim, traz-se aqui a realidade da gestão do Caps-i do Agreste por meio dessa narrativa obtida na pesquisa: "Trabalhamos com equipe mínima para uma demanda crescente, e até precisamos de alguns profissionais essenciais ao público infanto-juvenil, como fonoaudiólogo e terapeuta ocupacional, isso há mais de quatro anos" (Coordenador B).

No Caps-i da Região da Mata também houve relatos sobre a necessidade de ampliação da equipe profissional, como enfatiza um dos profissionais: "tivemos uma redução do quadro de profissionais da equipe multiprofissional... precisamos ampliar nossa equipe para dar essa desafogada nos grupos terapêuticos" (Profissional E). A fala desse profissional também elucida o problema referente à quantidade mínima de profissionais na equipe. O profissional salienta que não sabe se isso tem relação com os impactos da EC no 95/2016, mas informa que, nos últimos anos, houve uma redução do número de profissionais da equipe e de equipamentos, inclusive, a perda de um carro que era utilizado para os serviços do Capsi, o que trouxe impactos negativos para a efetivação da promoção dos serviços de saúde mental no Caps-i.

\section{Considerações finais}

Consideram-se as contribuições dos Centros de Atenção Psicossocial Infantojuvenis (Caps-i), dentro da lógica da atenção à saúde mental no Brasil, como sendo serviços fundamentais para a mudança do modelo 


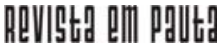

\} TRABALHANDO COM O MÍNIMO - SILVA, S. M. P.; FRANÇA, M. H. O. \}

DOI: $10.12957 /$ REP.2022.63445

hospitalocêntrico e biomédico, além de ser uma garantia da oferta da atenção psicossocial universal e integral. Esse serviço substitutivo ao manicomial trouxe consigo a ideia de liberdade, de inclusão, de fortalecimento dos vínculos familiares e sociais, bem como da garantia de direitos humanos fundamentais. Entretanto, conforme identificado no estudo conduzido, os Caps são fortes objetos para o ataque da precarização e sucateamento diante do processo contrarreformista do Estado brasileiro.

Destacou-se também que a diminuição do financiamento na saúde mental configura uma grave problemática que deve ser discutida com os profissionais e gestores e, especialmente, reconsiderada pelo Estado como forma de consolidar a garantia dessa política pública. Para tanto, urge a necessidade de revogação da EC no 95, de 2016, uma vez que configura um ataque grave à promoção da saúde mental infantojuvenil e à oferta dos serviços substitutivos nos Caps-i.

Além disso, a garantia de estruturas físicas adequadas para o funcionamento dos Caps-i também é de suma relevância para a qualidade dos serviços e para a melhoria da atuação dos profissionais quanto à oferta das ações e serviços nas unidades que se encontram precarizadas, conforme os resultados obtidos no presente estudo. No que tange à composição das equipes multiprofissionais, a pesquisa evidenciou que há necessidade de ampliação, ou seja, de mais contratação, e da inclusão de outras especialidades, pois as equipes são ínfimas em tamanho, diante da elevada demanda.

Embora a pesquisa traga apenas um recorte da realidade local, ela não se distingue do contexto nacional, ou seja, da gestão da política de saúde mental em outras regiões do país. Trata-se de uma expressão da questão social que revela precariedades na relação serviço-profissionalusuário e desafio cotidiano de se garantir ou não a efetivação do direito ao acesso aos serviços de atenção à saúde mental infantojuvenil, além de nos levar a repensar sobre novas estratégias para resistir e lutar pela defesa do acesso a essa política, com debates críticos e propositivos no meio acadêmico, profissional e social. Afinal, nesse nado contra a corrente, parafraseando Nise da Silveira, "não faz parte do vocabulário a palavra recuar, deve-se sempre ir em frente. Anda-se para o futuro"; ou seja, um futuro que garanta a manutenção de uma política de saúde mental infantojuvenil pública, de qualidade, integral e efetiva. 


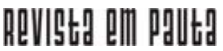

\} TRABALHANDO COM O MÍNIMO - SILVA, S. M. P.; FRANÇA, M. H. O. \}

DOI: $10.12957 /$ REP.2022.63445

\section{Referências}

AMARANTE, P. Análise do sanitarista Paulo Amarante sobre a nova política nacional de saúde mental. 2019. Disponível em: https://www.youtube.com/ watch?v=C58oTUjaJ3s. Acesso em: 16 maio 2021.

AMARANTE, P.; NUNES, M. O. A reforma psiquiátrica no SUS e a luta por uma sociedade sem manicômios. Ciência e Saúde Coletiva, v. 23, n. 6, 2018.

ARBEX, D. Holocausto brasileiro. São Paulo: Geração Editorial, 2013.

AZEVEDO, E. B. Rede de cuidado da saúde mental: tecendo práticas de inclusão social no município de Campina Grande. Dissertação (mestrado em Enfermagem em Saúde Pública - UFPB/CCS, João Pessoa, 2010. Disponível em: https://repositorio.ufpb.br/jspui/bitstream/tede/5187/1/arquivototal.pdf. Acesso em: 15 maio 2021.

BARDIN, L. Análise de conteúdo. São Paulo: Edições 70, 2011.

BEHRING, E. R. Brasil em contra-reforma: desestruturação do Estado e perda de direitos. São Paulo: Cortez Editora, 2008.

BRASIL. Ministério da Saúde. Portaria GM/MS n. 336, de 19 de fevereiro de 2002. 2002. Disponível em: http://bvsms.saude.gov.br/bvs/saudelegis/ gm/2011/prt3089_23_12_2011_rep.html. Acesso em: 20 maio 2021.

BRASIL. Ministério da Saúde. Secretaria-Executiva. Secretaria de Atenção à Saúde. Legislação em saúde mental: 1990-2004. Brasília, 2004.

BRASIL. Ministério da Saúde. Manual de estrutura física dos Caps. 2013. Disponível em: http://189.28.128.100/dab/docs/sistemas/sismob/manual ambientes_caps_ua.pdf. Acesso em: 9 dez. 2020.

BRASIL. Ministério da Saúde. Saúde mental em dados 12. 2015. Disponível em: https://www.mhinnovation.net/sites/default/files/downloads/innovation/ reports/Report_12- edicao-do-Saude-Mental-em-Dados.pdf. Acesso em: 6 nov. 2020.

CORREIA, L. C.; MARTINS, L.; REQUIÃO, M. À beira do abismo e ao encontro do absurdo: considerações sociojurídicas sobre a Nota Técnica n. 11/2019 do Ministério da Saúde. Revista Jurídica (Furb), v. 23, n. 50, jan./ abr. 2019.

DELGADO, P. G. G. A nova fronteira intersetorial ainda está por ser conquistada. Revista Radis: Comunicação em Saúde, n. 97, set. 2010.

GUERRA, Y. A instrumentalidade do Serviço Social. São Paulo: Cortez, 2002.

MARX, K. O capital: crítica da economia política. Vol. 1, tomo 1. São Paulo: Nova Cultural, 1988. 


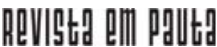

\} TRABALHANDO COM O MÍNIMO - SILVA, S. M. P.; FRANÇA, M. H. O.

DOI: $10.12957 /$ REP.2022.63445

MEDEIROS, A. P. A.; TOMÉ, C. A. Desafios para efetivação da política de atenção à saúde mental no Centro de Atenção Psicossocial Infantojuvenil (Capsi) de Patos/PB. 2018. Disponível em: https://repositorio.ifpb.edu.br/ jspui/bitstream/177683/927/1/TCC\%20vers\%C3\%A3 o\%20para \%20dep\%C3\%B3sito\%20no\%20polo.pdf. Acesso em: 13 jul. 2020.

TRAPÉ, T. L.; CAMPOS, R. O. Modelo de atenção à saúde mental do Brasil: análise do financiamento, governança e mecanismos de avaliação. Revista de Saúde Pública, v. 51, n. 19, 2017.

DOI: $10.12957 /$ rep.2022.63445

Recebido em 19 de junho de 2021.

Aprovado para publicação em 03 de setembro de 2021.

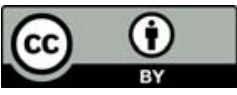

A Revista Em Pauta: Teoria Social e Realidade Contemporânea está licenciada com uma Licença Creative Commons Atribuição 4.0 Internacional. 